effects produced by insecticides and other pesticides on the food of animals or to study the breeding biology of birds nesting at artificially high densities produced by the use of nesting boxes.

The ecologist and the ornithologist will find this a stimulating and a thought provoking book which will act as a directive and a challenge for future research work. I am sure ecologists working on other groups will turn to this work as a guide for analytical studies in their own groups once the basic information is available. No doubt the methods will be modified, but this book will continue to have a reputation as a pioneer work in animal ecology for many years to come.

J. C. Coulson

\section{SENSORY PHYSIOLOGY}

\section{The Physiology of Sense Organs}

By De Forest Mellon, jun. (University Reviews in Biology.) Pp. vii + 107. (Oliver and Boyd: Edinburgh and London, August 1968.) $37 s 6 d$ hardback; $25 s$ paperback.

THE subject of the sense organs, like that of the nervous system in general, is one where a lot of information concerning particular details is available. Yet it is not possible at present to say with any certainty what common denominators underlie the spectrum of behaviour we observe. This makes it difficult to write a short introductory text, and the author is to be congratulated on having produced one that will be both most valuable to the honours graduate student and can be used as a useful introduction by others. In doing this, Dr Mellon has confined himself predominantly to invertebrate studies and has been undoubtedly wise to do so, as to have attempted to cover the whole field would have assuredly left the new reader with a less clear understanding of the problems than he can obtain here.

Sensory receptors have much in common with other excitable tissues, and it is natural that a good deal of the early part of the book should be concerned with covering this common ground. The author subsequently deals with those aspects of excitability that are more specific to tissues adapted as sense organs, and then considers these functions in relation to cell structure. The final chapter deals with the absorption of stimulus energy, and this is perhaps the wealiest section of the book, as here selection is so limited as to fail to indicate the scale of the problem. Nevertheless, the book as a whole can be recommended.

\section{C. Whitfield}

\section{CLASSICAL BIOPHYSICS}

\section{Membranes, lons and Impulses}

A Chapter in Classical Biophysics. By Kenneth S. Cole. Pp. viii + 569. (University of California Press: Berkeley and Los Angeles; Cambridge University Press: London, October 1968.) $142 s 6 d$.

Membranes, Ions and Impulses, by K. S. Cole, is an important work. Cole's book, for it will surely be known as that, is essential for anyone who wants to know how nerves conduct impulses, how excitable biological membranes behave, or who wants to think about the molecular basis of that complex behaviour. The first two sections describe the linear and non-linear electrical properties of cells and cell membranes, with special emphasis on the giant axon of the squid. "Taming the axon" by feedback control of the membrane potential showed that over a range of potentials the membrane conductance was negative as well as non-linear. The voltage-clamp method and the role of the ionic currents in the generation of the nervous impulse are discussed in the third part. Part four chronicles the extension of the voltage-clamp method to new experimental situations, and describes the results of work on a number of excitable cells up to the end of 1966. The final section, "Inside the Membrane", looks at the clues that we have to membrane mechanisms. This section is short, reflecting our present ignorance. It is also exciting as that ignorance is a major biophysical challenge.

Cole sub-titles his book "A Chapter in Classical Biophysics". It is an apt description, which serves as a reminder that physiology has always depended closely on the ideas and methods of physics and physical chemistry. Biophysics is not a new subject, even if it is a new name. Volta and Helmholtz would be surprised to learn that physics and biology had only recently achieved a new interdisciplinary synthesis; they might be forgiven for claiming to have done it first.

Cole's approach to the work he describes is avowedly historical, and he writes from the vantage point of one who has made many major contributions. Historical accounts of scientific success stories are interesting and important, but Cole provides, as well, formal presentations of the developed analyses. The steady progress towards the presently accepted mechanism of nervous conduction, a progress interrupted by the Second World War, was the result of ideas exchanged among numerous people. It is in the nature of science and history that there may be more agreement about the final ideas than about the events that lead to them. Cole would be the first to acknowledge the importance of this exchange, and does so in his generous appreciation of the work of colleagues, especially that of Hodgkin and Huxley for which a Nobel prize was given in 1963. A recent account of another Nobel-winning advance in biology seems to support a "breakthrough" hypothesis for the advancement of science; though undeniably more dramatic, it is probably exceptional.

The dust jacket of the book makes the claim that "elementary calculus and a willingness to learn have carried many readers through most of it". It is unfair to judge a book by its wrapper, but it should be recorded that this statement might mislead the enthusiastic biologist with meagre mathematics who would need to face analysis of impedance in the complex plane, Poisson's equation, Laplace's equation in vector form, and KramersKronig integrals, all within the first twenty pages of text. For the interested physicist a background knowledge of some physiology would certainly be helpful. Such a background is assumed by the author whose aim is to "teach [presumably to biologists] a little of the substance of physical sciences and their application to the problems of the living cell membrane". This aim is important, but although such a vigorously physical approach is welcome it is hard on a non-biological reader that so little attempt is made, even in passing, to see these problems in their biological context. (A pleasing exception is the elegant photograph of the North Atlantic squid in section two.) In particular a non-biological reader could finish the book and be almost unaware of the physical and chemical problems associated with the maintenance in living cells of the ionic concentration gradients upon which nervous conduction depends.

Much of the content of Membranes, Ions and Impulses has previously only been available in the original papers, and even then much that is made explicit here is only implicit there. A reader familiar with the field will often recognize the provenance of particular records and figures. It is sometimes inconvenient, however, that the figures, although in general excellently prepared, do not have references, except in the text, and where previously unpublished records are used for illustration this is not always indicated. It is a minor blemish in an otherwise well produced volume. Teachers, students and colleagues will all be enormously grateful to Cole for putting so much of his own enthusiasm, and of his knowledge, into this book.
R. H. ADRIAN 